\title{
Optimized Aircraft Electric Control System Based on Adaptive Tabu Search Algorithm and Fuzzy Logic Control
}

\author{
Saifullah Khalid \\ IET Lucknow, UP, India \\ e-mail: saifullahkhalid@Outlook.com
}

\begin{abstract}
Three is three conventional controls, i.e.: constant instantaneous power control, sinusoidal current control, and synchronous reference frame techniques for extracting reference currents for shunt active power filters. These methods have been optimized using Fuzzy Logic control and Adaptive Tabu search Algorithm and their performances have been compared. Critical analysis of Comparison of the compensation ability of different control strategies based on THD and speed will be done, and suggestions will be given for the selection of technique to be used. The simulated results using MATLAB model are presented, and they will clearly prove the value of the proposed control method of aircraft shunt APF. The waveforms observed after the application of filter will be having the harmonics within the limits and the power quality will be improved.
\end{abstract}

Keywords: Aircraft electrical system, Shunt Active Filter (APF); constant instantaneous power control strategy; Synchronous reference frame strategy; harmonic compensation; fuzzy logic; Adaptive Tabu search algorithm

\section{Introduction}

More advanced aircraft power systems [1]-[3] have been needed due to increased application of electrical power in place of other alternate power sources. The subsystems like flight control, flight surface actuators, passenger entertainment, etc. are driven using electric power, which consecutively increased the demand for creating aircraft power system more intelligent and advanced. These subsystems have considerable increased electrical loads i.e. power electronic devices, increased consumption of electrical energy, more demand for power, and over to all of that; much more stability and power quality problems.

In distinction to normal supply system source frequency of $50 \mathrm{~Hz}$, aircraft AC power system is using source frequency of $400 \mathrm{~Hz}$ [1]-[3]. Aircraft power utility is having source voltage of $115 / 200 \mathrm{~V}$. The loads associated with the aircraft a system are dissimilar from the normal loads used in $50 \mathrm{~Hz}$ supply system [1]. When we consider as the generation portion; aircraft system will remain AC driven from the engine for aircraft primary power. Fuel cell technology can be used to generate a DC output for ground power where its silence process would match up to adequately with the Auxiliary Power Unit (APU). However when considering the distribution of primary power, whether AC or DC; each approach has its merits. In DC distribution, HVDC power distribution systems permit the most resourceful employ of generated power by antithetical loss from skin effect. This allows paralleling and loads sharing among the generators. In AC distribution, Switching of $A C$ is very clear-cut even at high levels as it logically has a zero crossing point. Due to its high reliability over HVDC system, a wide range of Contactors, Relays can be exploited.

While talking about Aircraft Power Systems we also need to consider increased power electronics application in aircraft which creates harmonics, large neutral currents, waveform distortion of both supply voltage and current, poor power factor, and excessive current demand. Besides if some non-linear loads are impressed upon a supply, their effects are additive. Due to these troubles, there may be nuisance tripping of circuit breakers or increased loss and thermal heating effects that may provoke early component failure. This is a very large problem to any motor loads on the system. Therefore, good power quality of the generation system is of particular attention to the Aircraft manufacturer. We know that aircraft systems work on high 
frequency so even on the higher frequencies in the range of 360 to $900 \mathrm{~Hz}$; these components would remain very significant.

Today, advance soft computing techniques are used widely in the automatic control system or for optimization of the system applied. Some of them are such as fuzzy logic [4]-[8], optimization of active power filter using GA[9]-[12], power loss minimization using particle swarm optimization [13], neural network control [14]-[18] applied in both machinery and filter devices. GA has been applied to determine value of inductor filter $\left(L_{f}\right)$ [30]. GA will try to search the best value of the filter inductor for the optimization of the system [30]. PSO has been applied in aircraft system to find $s$ a secondary heading and attitude computation method with the velocity information output by Air Data System (ADS). The algorithm, based on PSO for the parameter identification, estimates and revises the parameters of observation module, consequently achieves optimal estimation of heading and attitude [31]. ANN has been used for the betterment of the conventional control strategy used and the results prove the effectiveness [3].

In this paper, Fuzzy logic controller and Adaptive Tabu search Algorithm (ATS) have been used to improve the overall performance of active filter for reduction of harmonics and others problem created into the aircraft electrical system due to the non-linear loads [1]. The comparisons of offline and online intelligent techniques have been checked by comparing the Fuzzy logic controller and Adaptive Tabu search Algorithm (ATS). The simulation results clearly show their effectiveness. The simulation results obtained with the new model are much better than those of traditional methods.

The paper has been structured in the following manner. The APF configuration and the load under consideration are discussed in Section II. The control algorithm for APF is discussed in Section III. MATLAB/ Simulink based simulation results are discussed in Section IV, and finally Section $\vee$ concludes the paper.

\section{System Description}

The aircraft system is a three-phase power system with source frequency of $400 \mathrm{~Hz}$. As exposed in Figure 1, Shunt Active Power Filter improves the power quality and compensates the harmonic currents in the system [22], [24]-[25], [27]-[28]. The shunt APF is comprehended by using one voltage source inverters (VSIs) connected at the point of common coupling (PCC) with a common DC link voltage [20]-23].

The set of loads for aircraft system consist of three loads. The first load is a three-phase rectifier in parallel with an inductive load and an unbalanced load connected in a phase with the midpoint (Load 1). The second one is a three-phase rectifier connects a pure resistance directly (Load 2). The third one is a three-phase inductive load linked with the ground point (Load 3). Finally, a combination of all three loads connected with system together at a different time interval to study the effectiveness of the control schemes has been used to verify the functionality of the active filter in its ability to compensate for current harmonics. For the case of all three load connected, Load 1 is always connected, Load 2 is initially connected and is disconnected after every 2.5 cycles, Load 3 is connected and disconnected after every half cycle. All the simulations have been done for 15 cyclesThe values of the circuit parameters are given in Appendix.

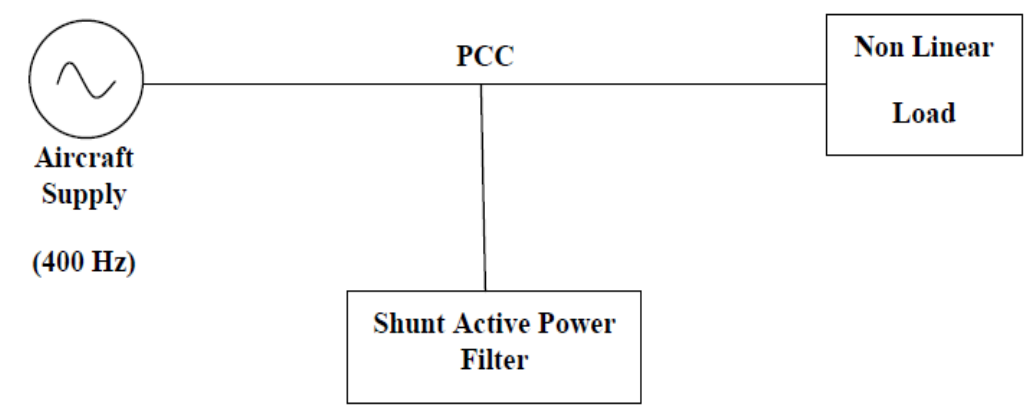

Figure 1. Aircraft system using Shunt Active Power Filter 


\section{Control Theory}

The proposed control of APF depends on three different control strategies, and all these strategies have been optimized with an artificial intelligent technique like fuzzy logic control and Adaptive Tabu search Algorithm. All three control strategies have been discussed in brief in this section. The following section also deals with the basic application of fuzzy logic and ATS Algorithm in all three control schemes [19], [20], [29].

\subsection{Constant Instantaneous Power Control Strategy (C.I.P.C.)}

Figure 2 shows the control diagram of the shunt active filter using constant instantaneous power control strategy. We can see that four low pass filters have been shown in the control block; in which, three with cut off of $6.4 \mathrm{KHz}$ has been applied to filter the voltages and one for the power $p_{0}$. Due to instability quandary, direct application of the phase voltages cannot be used in the control. There may be resonance among source impedance and the small passive filter. Low pass filters have been applied to the system to block the voltage harmonics at the resonance frequency that are higher than $6.4 \mathrm{KHz} . \mathrm{P}, \mathrm{q}, \mathrm{p}_{0}, \mathrm{v}_{\alpha}$ and $\mathrm{v}_{\beta}$ are attained after the calculation from $\alpha-\beta-0$ transformation and send to the $\alpha-\beta$ current reference block, which calculates $\mathrm{I}_{c \alpha}$ and $\mathrm{i}^{\prime} \mathrm{c}_{\beta}$. Finally, $\alpha-\beta-0$ inverse transformation block computes the current references and apply it to the PWM current control i.e. hysteresis band controller.

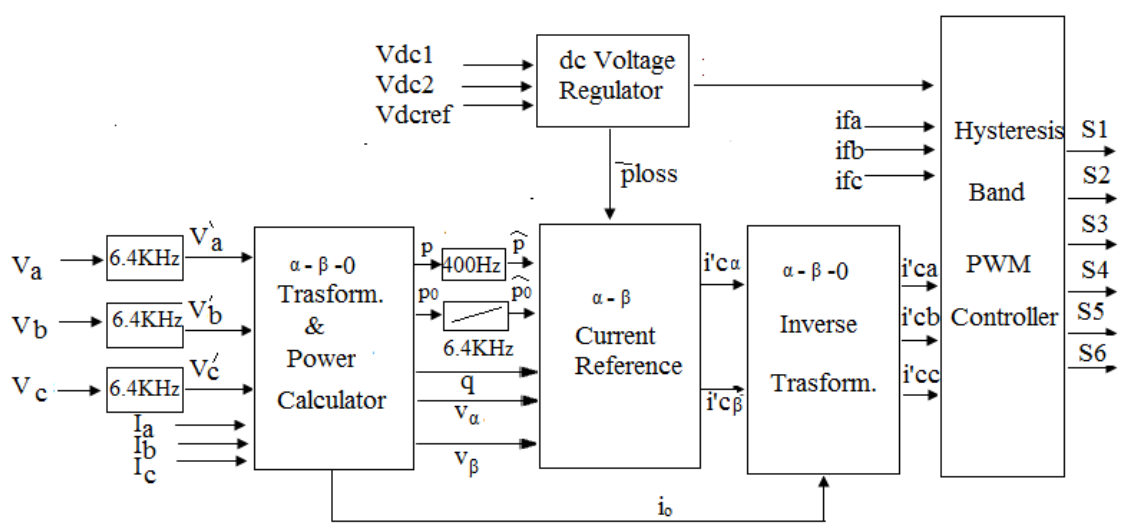

Figure 2. Control block diagram of the shunt active filter using constant source instantaneous power strategy

\subsection{Sinusoidal Current Control Strategy (S.C.C.)}

The sinusoidal current control strategy is a modified version of constant instantaneous power control strategy, which can compensate load currents under unbalanced states too. The modification includes a positive sequence detector that replaces the $6.4 \mathrm{KHz}$ cutoff frequency low-pass filters and exactly finds the phase angle and frequency of the fundamental positive sequence voltage component and thus shunt active power filter compensates the reactive power of the load. While designing this detector, the extreme concern should be taken so that shunt active filter produces ac currents orthogonal to the voltage component. Otherwise it will produce active power. $i_{\alpha}, i_{\beta}, p^{\prime}$ and $q^{\prime}$ are attained after the calculation from $\alpha-\beta-0$ transformation block and send to the $\alpha-\beta$ reference voltage block, which calculates $v_{\alpha^{\prime}}$ and $v_{\beta}$. Lastly, $\alpha-\beta-0$ inverse transformation block calculates the V'sa, V'sb and V'sc. Instead of the filtered voltages used previously, $\mathrm{Vsa}, \mathrm{Vsb}$ and $\mathrm{Vsc}$ are considered as input to the main control circuit of figure 3. Now fundamental negative sequence power, harmonic power, and the fundamental reactive power, are also incorporated in the compensating powers. 


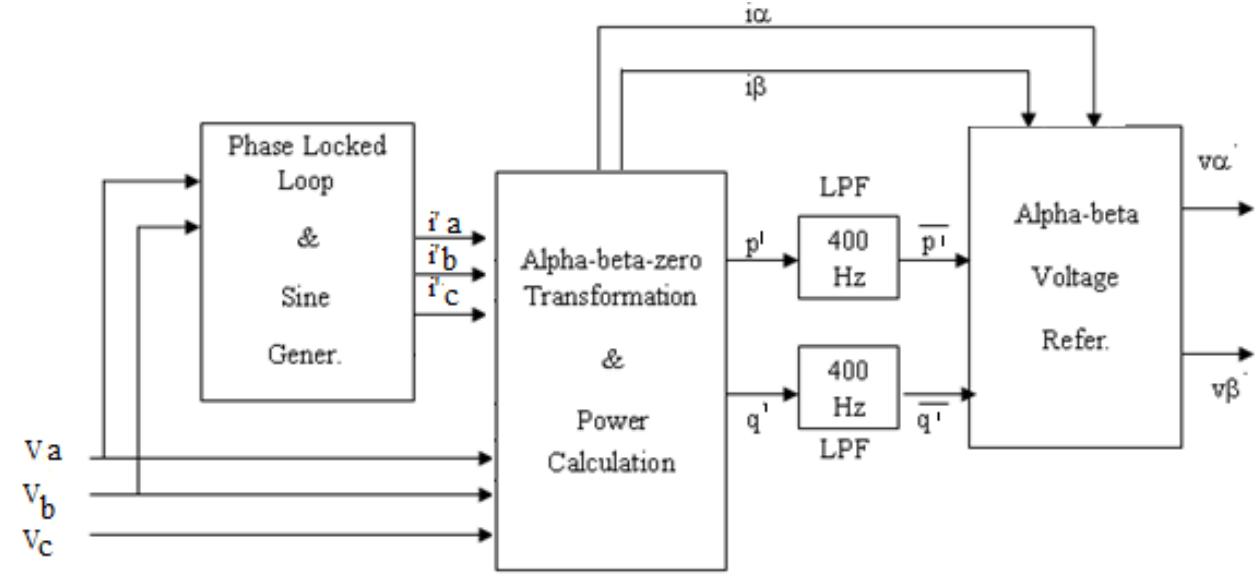

Figure 3. Block diagram of the fundamental positive-sequence voltage detector for sinusoidal current control strategy

\subsection{Synchronous Reference Frame Strategy (S.R.F)}

In this strategy, the reference frame $d-q$ is decided by the angle $\theta$ on the $\alpha-\beta$ frame applied in the p-q theory. Slight modifications are required in the conventional SRF method so that they can be used in aircraft power utility and compensate well the neutral current. For this reasons, zero-sequence component of current has not been well thought-out and so, the zero sequence subtract block cart off the zero sequence current from the load current and output current comprises of only positive sequence and negative sequence component and after its park transformation, the output current in $d$-q frame is composed of only instantaneous active and reactive current. A low-pass filter accomplishes the division of the dc and ac component of the active current for compensation of the harmonic and reactive current. This active current goes by a low pass filter, and the signal came from dc voltage regulator together though a Park counter-transformation subtracting from the load currents generates the reference current.

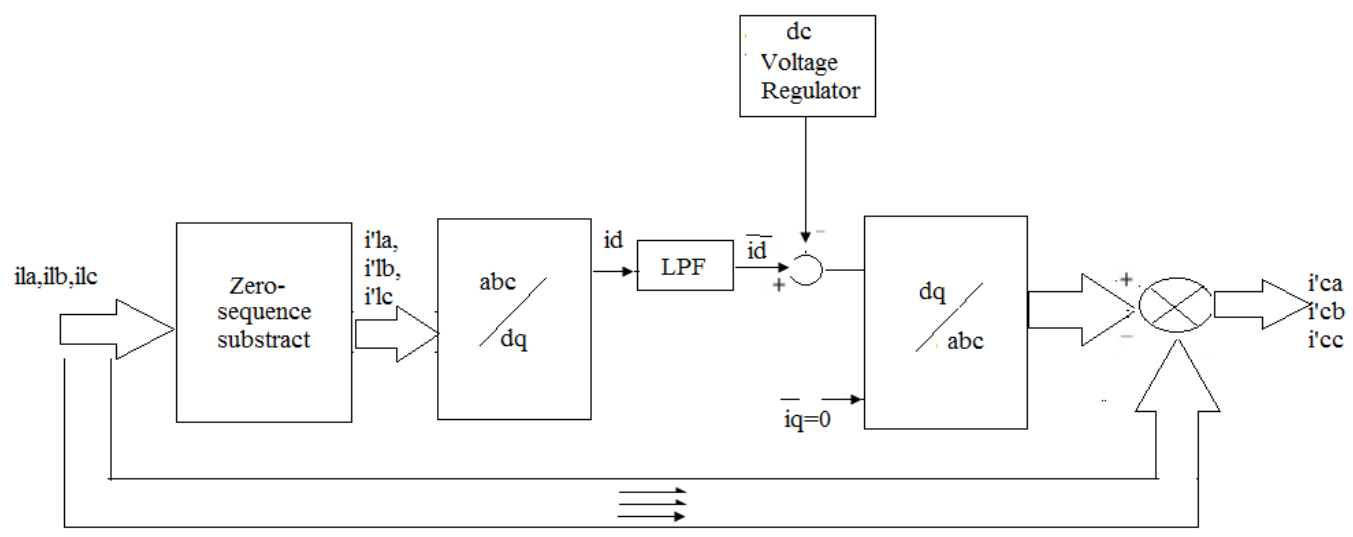

Figure 4. Control block diagram of the shunt active filter using synchronous reference frame strategy

\subsection{Fuzzy Logic Control}

The fuzzy logic control has been used in the dc voltage control loop of the active power filter. In fuzzy, the design uses centrifugal defuzzification method. There are two inputs; error and its derivative and one output, which is the command signal. The two inputs uses Gaussian membership functions while the output uses triangle membership function. Table 1 presents the fuzzy control rule and Figure 5 shows the membership functions used. 


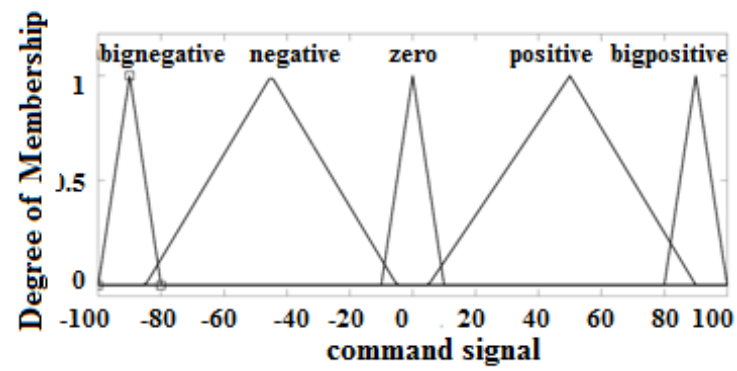

Figure 5. Membership functions

Table 1. Fuzzy Control Rule

\begin{tabular}{|c|c|c|c|}
\hline Error & Negative & Zero & Positive \\
\hline Negative & Big & Positive & Big \\
\hline Zero & $\begin{array}{l}\text { Negative } \\
\text { Big } \\
\text { Negative }\end{array}$ & Zero & $\begin{array}{c}\text { Positive } \\
\text { Big } \\
\text { Positive }\end{array}$ \\
\hline Positive & $\begin{array}{c}\text { Big } \\
\text { Negative }\end{array}$ & Negative & $\begin{array}{c}\text { Big } \\
\text { Positive }\end{array}$ \\
\hline
\end{tabular}

\subsection{Adaptive Tabu Search}

Adaptive Tabu Search (ATS) is a modified version of original tabu search formula for combinational optimization problem suggested by Glover. This method is very effective for solving non-linear continuous optimization problems. The modification that has been added into the new version is discretized continuous search space, back-tracking and adaptive radius.

The proposed ATS method searches the optimum value of the proportional integral controller parameters i.e. $K_{p}$ and $K_{I}$ and the objective function is decided such as to give their optimum value with the conditions of minimum overshoot, rise time and settling time. Boundary of $\mathrm{Kp}$ and $\mathrm{Ki}$, their upper limits and lower limits, then radius value, conditions for ATS back tracking, objective function and stop criteria has been defined. Maximum Searching iteration (500 rounds) for ATS has been set as stop criterion. Figure 6 shows the flow chart for the search of parameters using adaptive tabu search method.

The whole system based on three control strategies [24], [29] [31] have been simulated using MATLAB/Simulink to give the filter currents that will compensate the harmonics and make the system clean and well within standard limit [26]. 


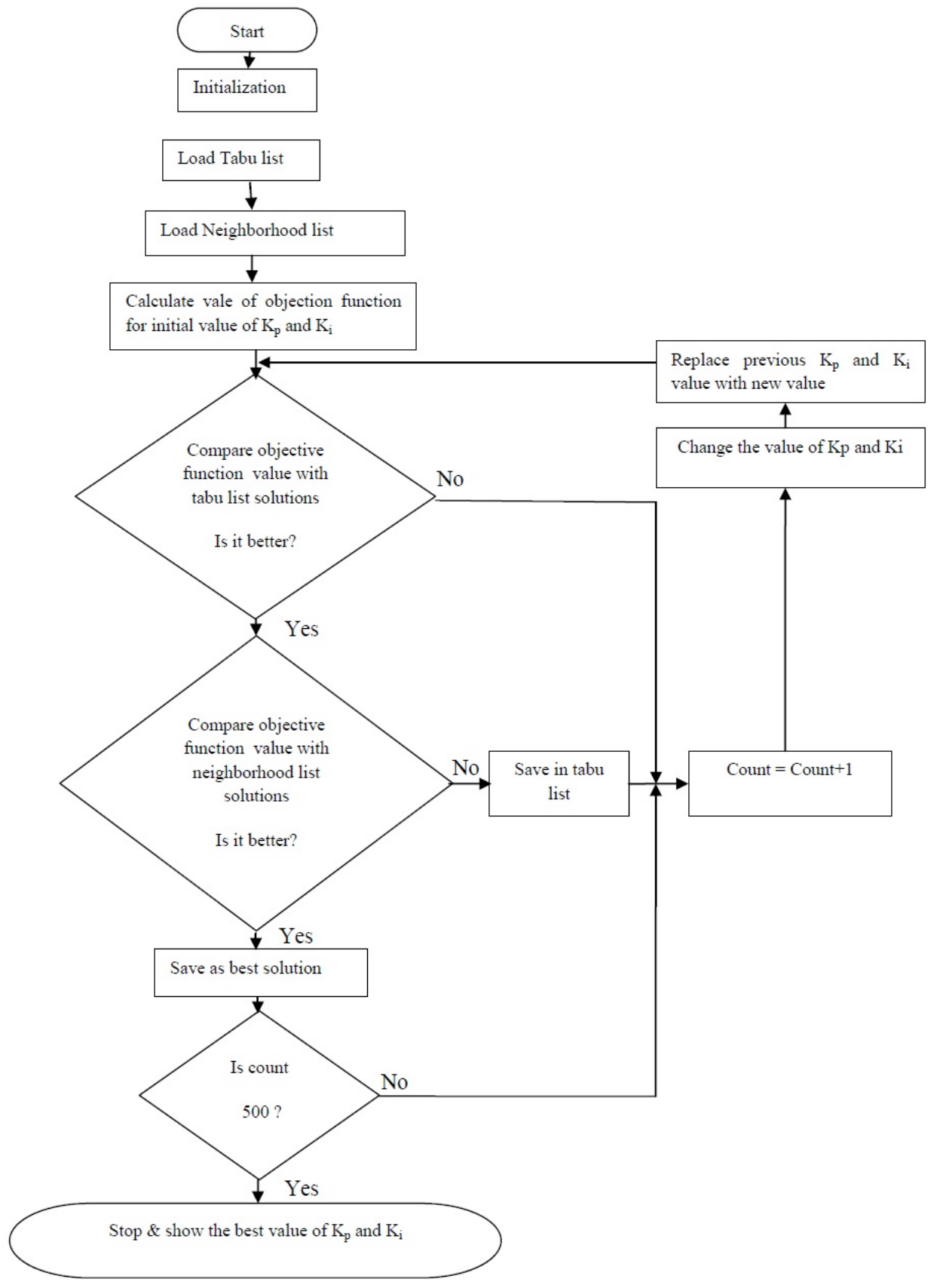

Figure 6. Flow chart for search of parameters using ATS

\section{Simulation Results \& Discussions}

The proposed scheme of APF is simulated in MATLAB environment to estimate its performance. Three loads have been applied together at a different time interval to check the effectivity of the control schemes in the reduction of harmonics. To appreciate compensation by APF, a small inductance is connected at the terminals of the load. The simulation results clearly reveal that the scheme can successfully reduce the significant amount of THD in source current and voltage within limits.

\subsection{Uncompensated System}

After doing simulation in MATLAB/Simulink without using any filter (Figure 7) i.e. for Uncompensated System, it has been observed that the THD of source current calculated when 
loads connected with the system is $9.5 \%$ and THD of source Voltage were $1.55 \%$. By observing these data, we can easily recognize supply has been polluted when loads have been connected and is obviously not within the limit of the international standard
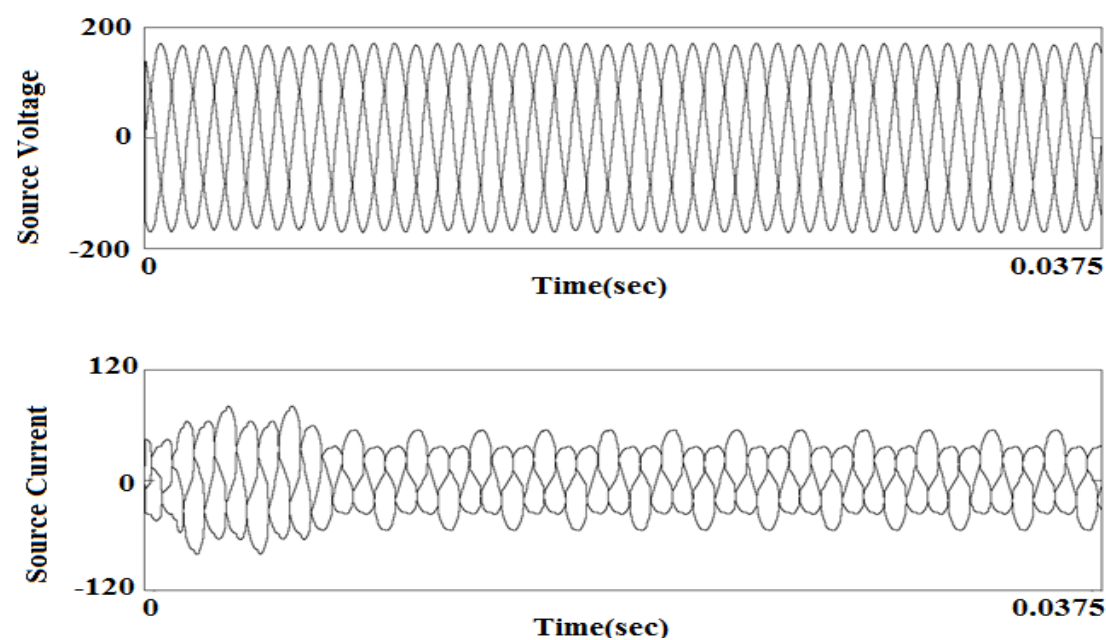

Figure 7. Source Voltage and source current waveforms of uncompensated system

The performance of APF under different loads connected, when utilizing fuzzy Logic \& ATS Algorithm, have been discussed below for all three conventional control strategy has have been given below.

\subsubsection{For Constant Source Instantaneous Power Control Strategy using Fuzzy Logic Controller}

From Figure 8 it has been empiric that that the THDs of source current and source voltage were $2.33 \%$ and $1.03 \%$ respectively. The compensation time was $0.0044 \mathrm{sec}$. At $\mathrm{t}=0.0044 \mathrm{sec}$, it is apparent that the waveforms for source voltage and source current have become sinusoidal. Figure 8 shows the waveforms of compensation current, dc capacitor voltage, and load current.

The aberration in dc voltage can be acutely apparent in the waveforms. As per claim for accretion the compensation current for accomplishing the load current demand, it releases the energy, and after that it accuses and tries to achieve its set value. If we carefully observe, we can acquisition out that the compensation current is in fact accomplishing the appeal of load current and afterward the active filtering the source current and voltage is affected to be sinusoidal.

\subsubsection{For Sinusoidal Current Control Strategy using Fuzzy Logic Controller}

The results from simulation are shown in figure 9. From the results, it is found that the THDs of source current \& source voltage were $2.22 \%$ and $1.01 \%$ respectively. At $t=0.0066 \mathrm{sec}$, we can see that the waveforms for source voltage and source current have become sinusoidal. The observed compensation time was $0.0066 \mathrm{sec}$.

The waveforms of compensation current, dc capacitor voltage and load current can be seen from figure 9 . There is variation in dc voltage which can be seen clearly in the waveforms. If there is need of increasing the compensation current for fulfilling the demand of load current, it releases the energy and after that it charges and tries to regain its set value.

\subsubsection{For Synchronous Reference Frame Strategy using Fuzzy Logic Controller}

THDs of source current \& source voltage have been found $2.30 \%$ and $1.10 \%$ respectively after making observations from the simulation results shown in figure 10 . The waveforms for source voltage and source current have become sinusoidal at $\mathrm{t}=0.0067 \mathrm{sec}$. Compensation time is $0.0067 \mathrm{sec}$. 

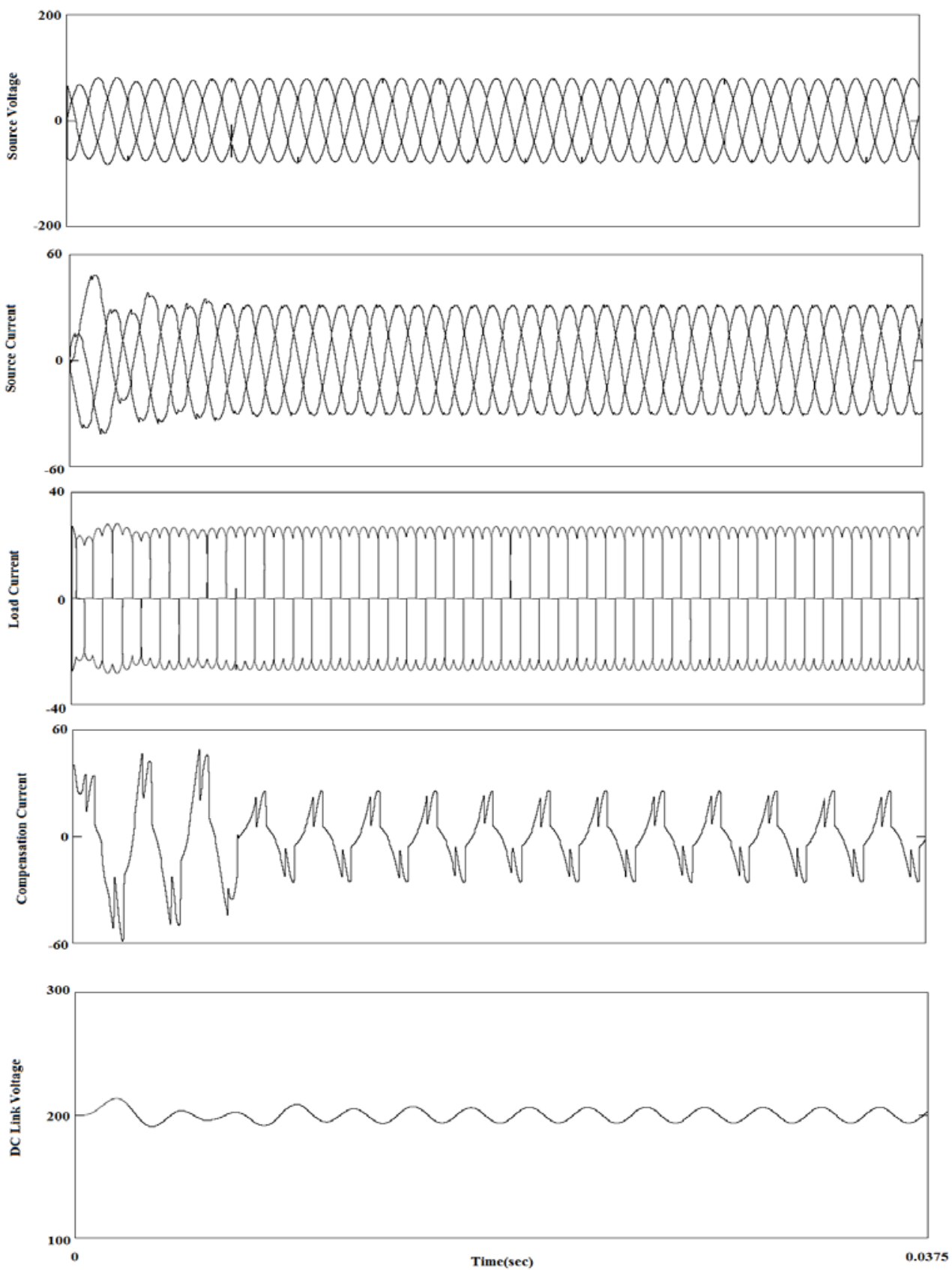

Figure 8. Source Voltage, source current, compensation current (phase b), DC link Voltage and load current waveforms of Active power filter using constant source instantaneous power strategy using fuzzy logic controller 

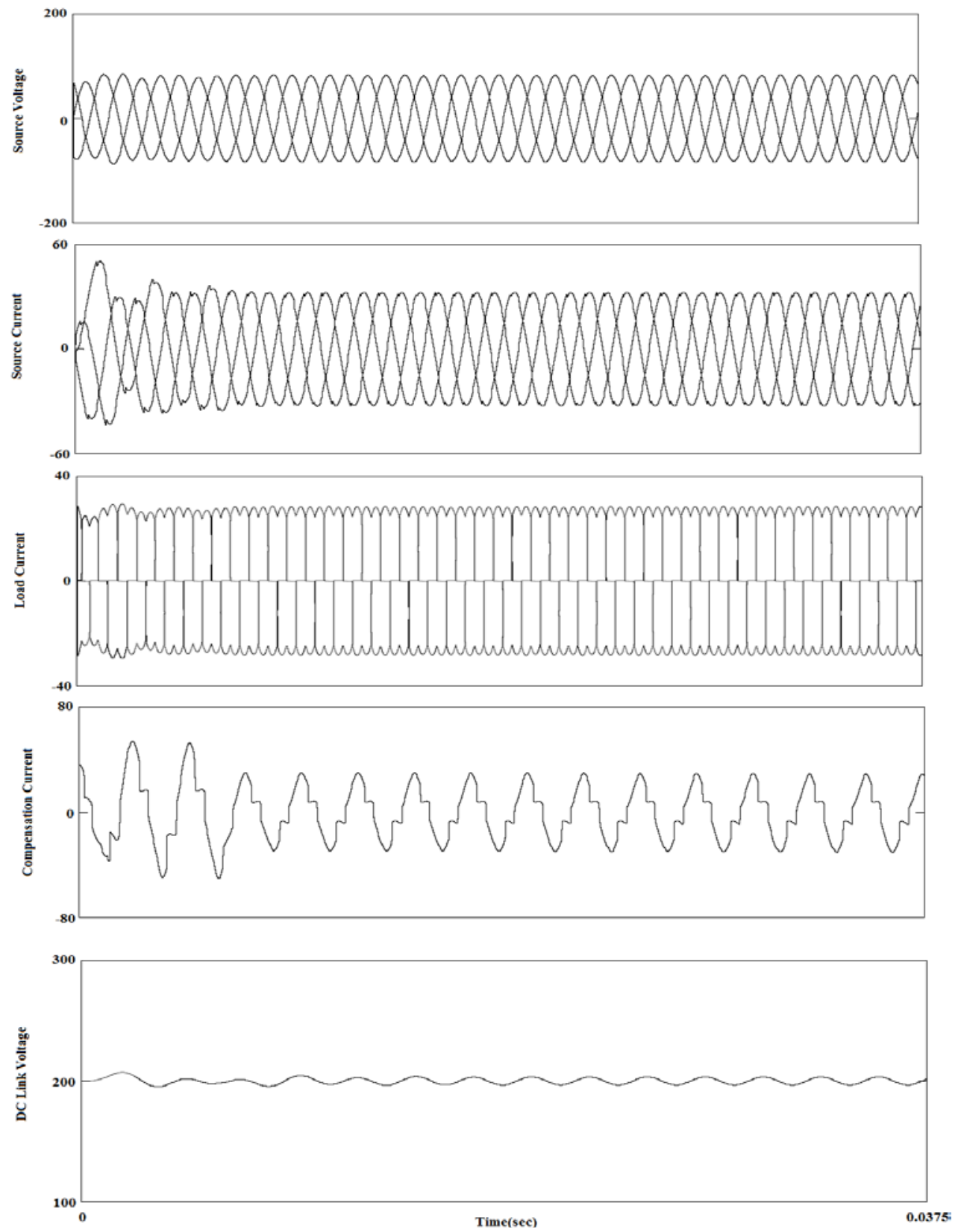

Figure 9. Source Voltage, source current, compensation current (phase b), DC link Voltage and load current waveforms of Active power filter using sinusoidal current control strategy using Fuzzy Logic Controller 

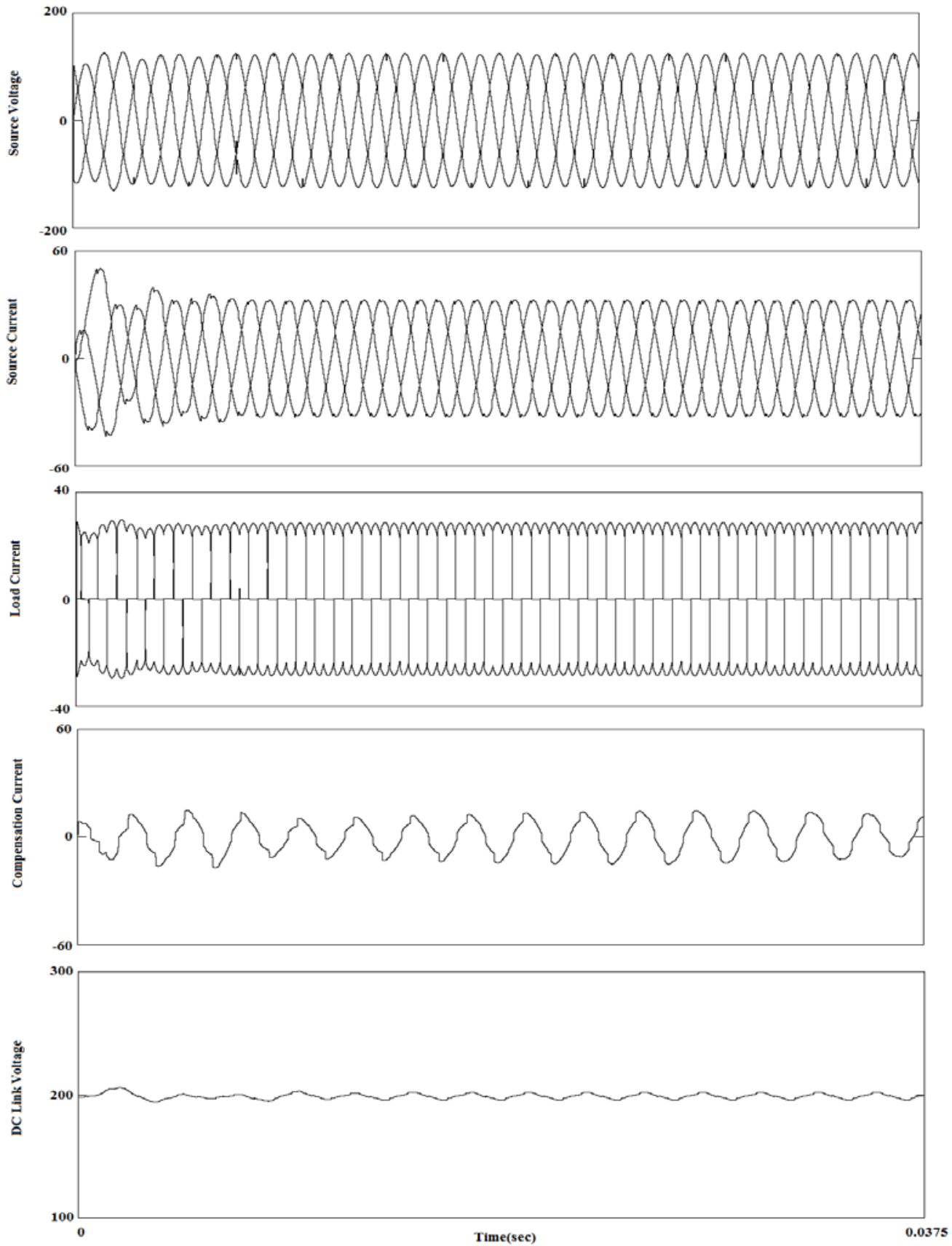

Figure 10. Source Voltage, source current, compensation current (phase b), DC link Voltage and load current waveforms of Active power filter using synchronous reference frame strategy using Fuzzy Logic Controller

\subsubsection{For Constant Source Instantaneous Power Strategy using ATS Algorithm}

THDs of source current \& source voltage have been found $2.72 \%$ and $1.07 \%$ respectively after making observations from the simulation results shown in figure 11 . The waveforms for source voltage and source current have become sinusoidal at $t=0.0064 \mathrm{sec}$. Compensation time is $0.0064 \mathrm{sec}$. The waveforms of compensation current, dc capacitor voltage and load current have been shown in figure 11 . Waveforms show the variations in dc capacitor voltage.

Whenever the demand of high load current comes, it releases the energy which in turn increases the compensation current. Later on, it charges and tries to regain its previous set 
value. By making a simple observation, we can say that compensation current is actually fulfilling the demand of load current. After the active filtering, the source current and voltage is forced to be sinusoidal.

\subsubsection{For Sinusoidal Current Control Strategy using ATS Algorithm}

The results from simulation are shown in figure 12. From the results, it is found that the THDs of source current \& source voltage were $2.42 \%$ and $1.06 \%$ respectively. At $t=0.0065 \mathrm{sec}$, we can see that the waveforms for source voltage and source current have become sinusoidal. The observed compensation time was $0.0065 \mathrm{sec}$.

The waveforms of compensation current, dc capacitor voltage and load current can be seen from figure 12. There is variation in dc voltage which can be seen clearly in the waveforms. If there is need of increasing the compensation current for fulfilling the demand of load current, it releases the energy and after that it charges and tries to regain its set value.

\subsubsection{For Synchronous Reference Frame Strategy using ATS Algorithm}

THDs of source current \& source voltage have been found $2.62 \%$ and $1.01 \%$ respectively after making observations from the simulation results shown in figure 13 . The waveforms for source voltage and source current have become sinusoidal at $t=0.0068 \mathrm{sec}$. Compensation time is $0.0068 \mathrm{sec}$. The waveforms of compensation current, dc capacitor voltage and load current have been shown in figure 13. Waveforms show the variations in dc capacitor voltage.

Whenever the demand of high load current comes, it releases the energy which in turn increases the compensation current. Later on, it charges and tries to regain its previous set value. By making a simple observation, we can say that compensation current is actually fulfilling the demand of load current. After the active filtering, the source current and voltage is forced to be sinusoidal. 

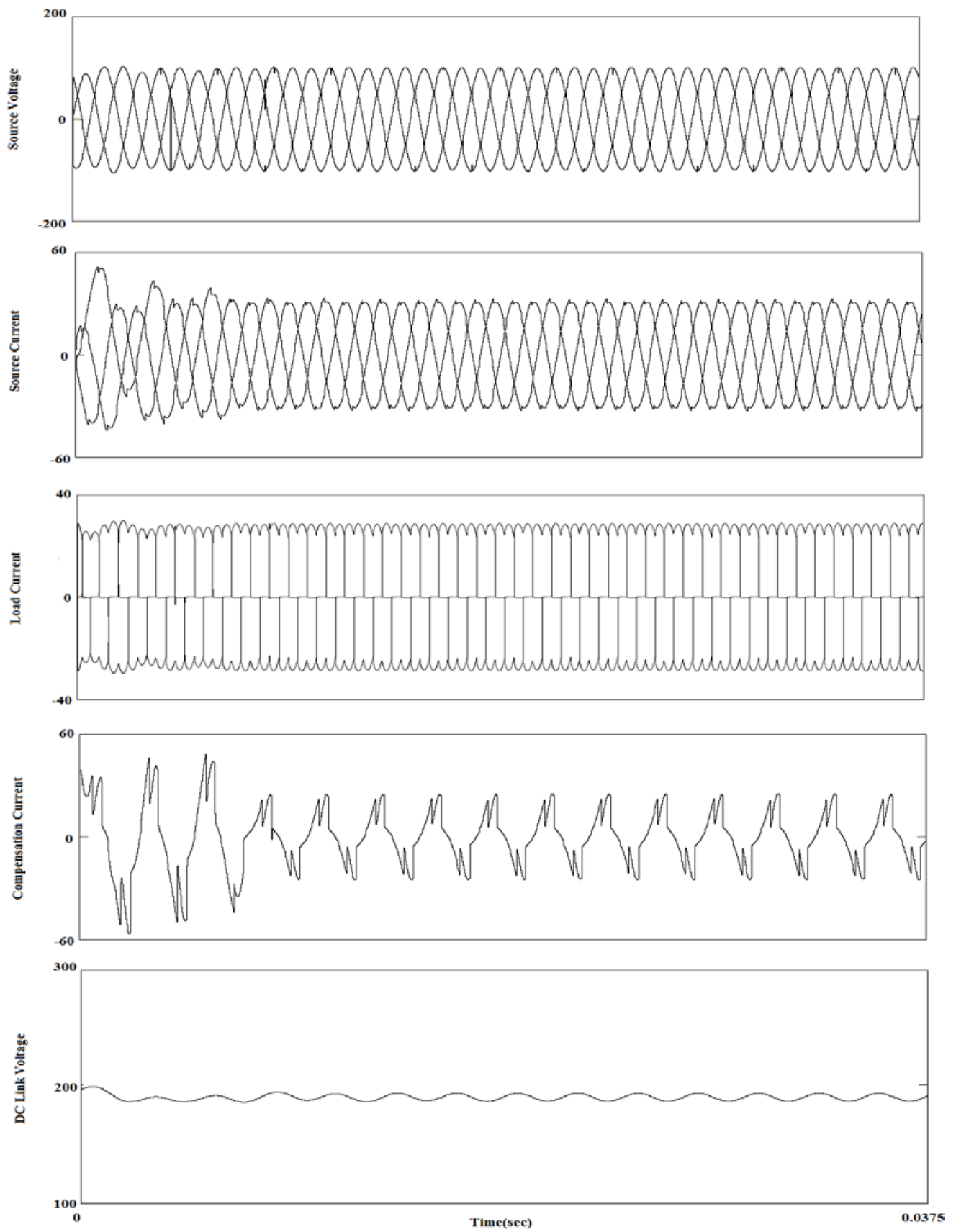

Figure 11. Source Voltage, source current, compensation current (phase b), DC link Voltage and load current waveforms of Active power filter using constant source instantaneous power strategy using ATS Algorithm 

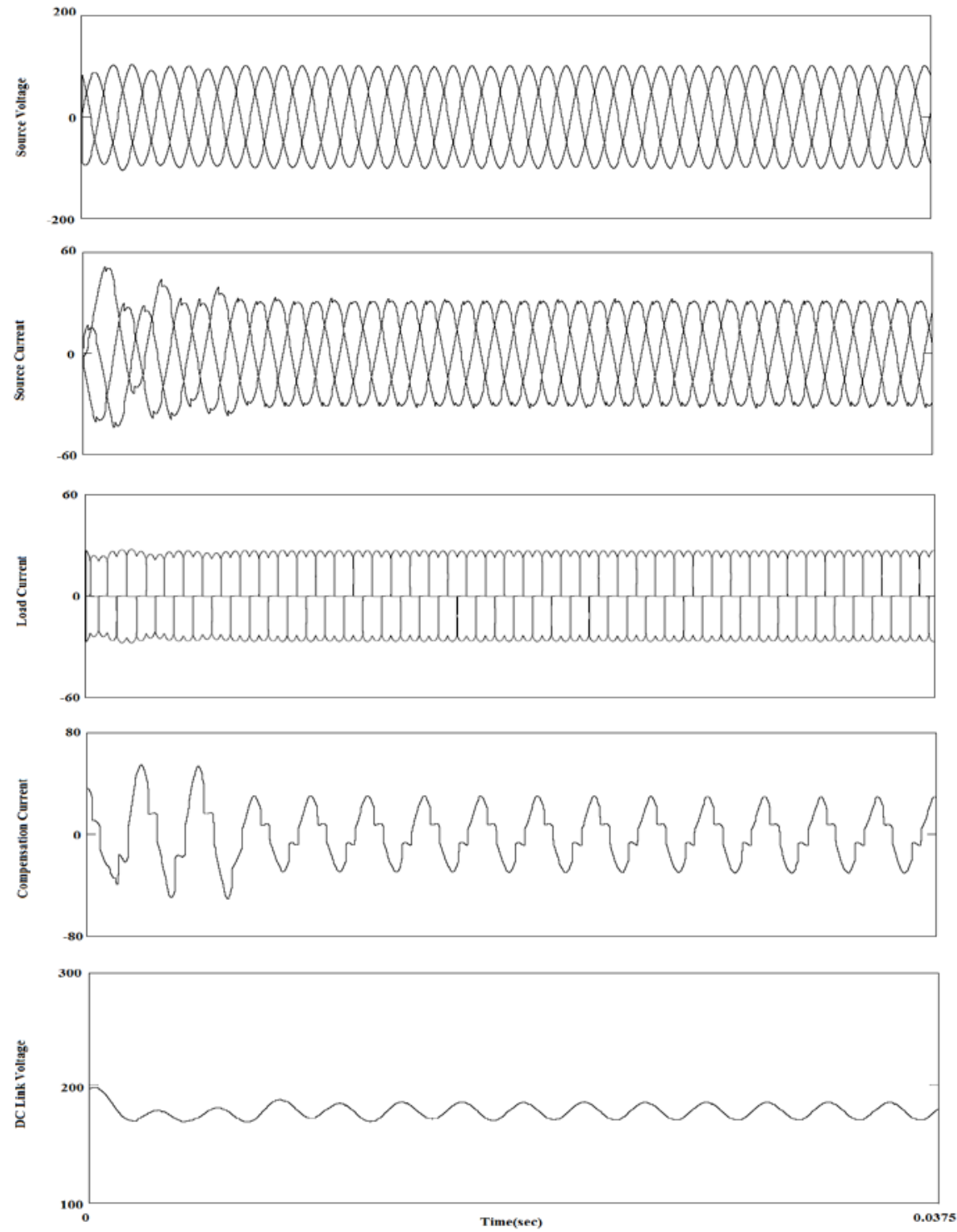

Figure 12. Source Voltage, source current, compensation current (phase b), DC link Voltage and load current waveforms of Active power filter using sinusoidal current control strategy using ATS Algorithm 

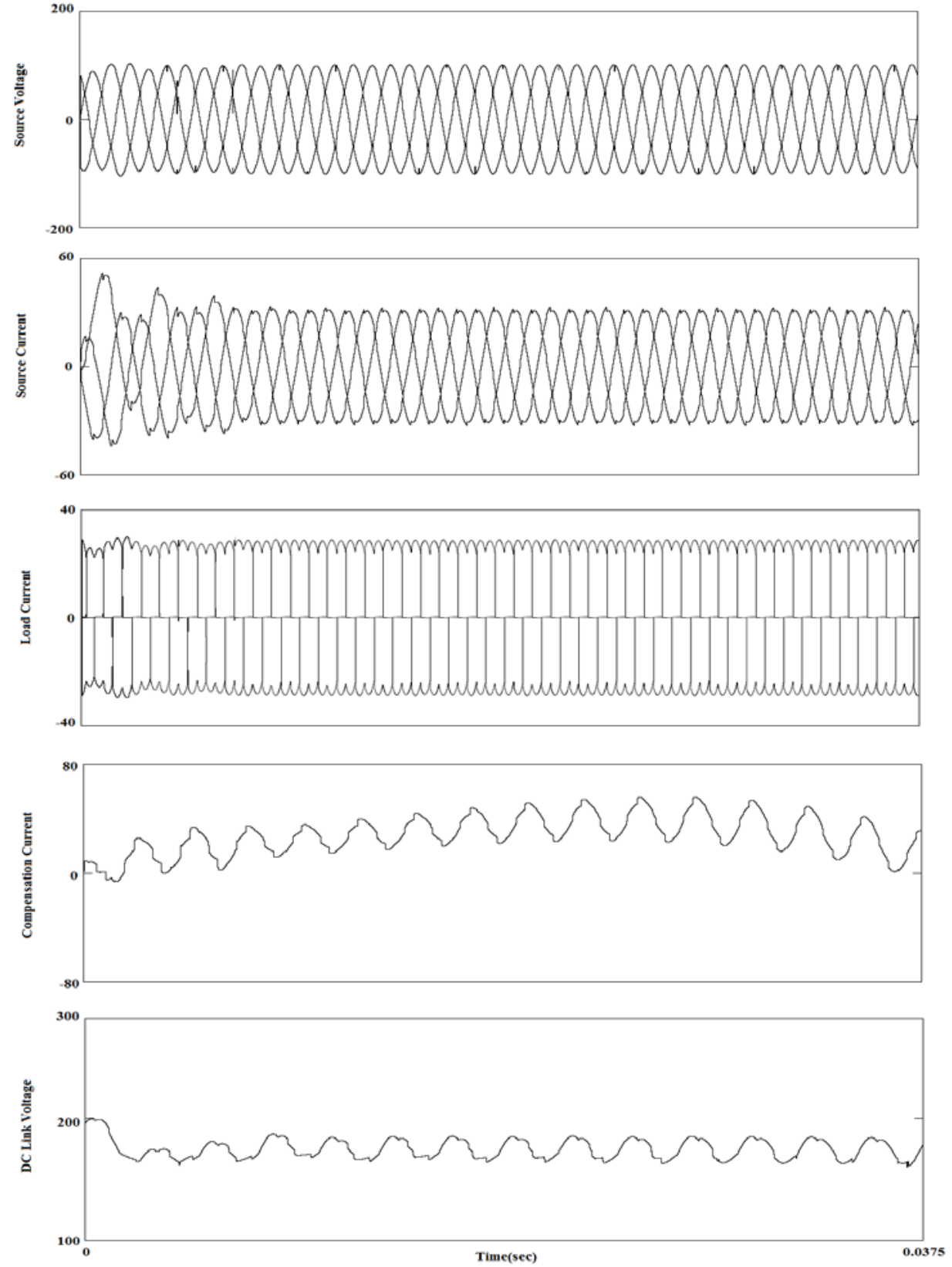

Figure 13. Source Voltage, source current, compensation current (phase b), DC link Voltage and load current waveforms of Active power filter using synchronous reference frame strategy using ATS Algorithm

\subsection{Comparative Analysis of the Simulation Results}

Simulation results have been tabulated in Table 1 . From the table 1 , we can easily say that Sinusoidal current control strategy (SCC-Fuzzy) has been found best for current and voltage harmonic reduction. Whereas synchronous reference frame strategy (SRF-ATS) was equally best as SCC-Fuzzy strategy for current compensation. When these results have been compared based on compensation time, it has been found that CIPC-Fuzzy strategy is fastest among all strategy. These conclusions have been also tabulated in Table 2. 
Table 1. Summary of Simulation Results using APF for Control Strategies using Fuzzy Logic

\begin{tabular}{cccc}
\multicolumn{4}{c}{ Controller \& ATS Algorithm } \\
\hline Strategy & $\begin{array}{c}\text { THD-I } \\
(\%)\end{array}$ & $\begin{array}{c}\text { THD-V } \\
(\%)\end{array}$ & $\begin{array}{c}\text { Compensation } \\
\text { Time }(\mathrm{sec})\end{array}$ \\
\hline CIPC-FUZZY & 2.33 & 1.03 & 0.0044 \\
SCC-FUZZY & 2.22 & 1.01 & 0.0066 \\
SRF-FUZZY & 2.30 & 1.10 & 0.0067 \\
CIPC-ATS & 2.72 & 1.07 & 0.0064 \\
SCC-ATS & 2.42 & 1.06 & 0.0065 \\
SRF-ATS & 2.62 & 1.01 & 0.0068 \\
\hline
\end{tabular}

Table 2. Comparison of strategies used for aircraft power utility

\begin{tabular}{cc}
\hline Compensation Units & Best Strategy \\
\hline THD-I(\%) & SCC-Fuzzy \& SRF-ATS \\
THD-V (\%) & SCC-Fuzzy \\
Compensation Time (Sec) & CIPC-Fuzzy \\
\hline
\end{tabular}

The simulation results shown and the tabulated in table $1 \& 2$ undoubtedly explains the choice of different strategy with different load based on THD and compensation time.

\section{Conclusion}

This paper has done a critical analysis of different conventional and soft computing control strategies for shunt APFs installed in aircraft power utility of $400 \mathrm{HZ}$. The ideas have been given for the optimum selection of strategy based on compensation time and THDs of source current and voltage. Overall Sinusoidal current control strategy (SCC-Fuzzy) has been observed as most fit and Synchronous reference frame strategy (SRF-ATS) found to be equally best for current compensation. Constant Instantaneous Power Control Strategy's performance has been improved and it becomes the fastest among all strategies simulated.

\section{References}

[1] Chen Donghua, Tao Guo, Shaojun Xie, Bo Zhou. "Shunt Active Power Filters Applied in the Aircraft Power Utility". 36th Power Electronics Specialists Conference, PESC '05, IEEE. 2005: 59-63.

[2] Khalid Saifullah, Dwivedi Bharti. Comparative Evaluation of Various Control Strategies for Shunt Active Power Filters in Aircraft Power Utility of $400 \mathrm{~Hz}$. Majlesi Journal of Mechatronic Systems. 2014; 3(2): 1-5.

[3] Khalid Saifullah, Dwivedi Bharti. Application of Al techniques in implementing Shunt APF in Aircraft Supply System. Proceeding of SPRINGER-SOCROPROS Conference, IIT-Roorkee. 2013; 1: 333341.

[4] Guillermin P. Genetic Algorithm Applied to Motor Control. IEEE Transactions on Industrial Application. 1996; 32(1): 51-56.

[5] Abdul Hasib A, Hew Wooi P, Hamzah A, Mowed HAF. Genetic Algorithm of a three phase Induction Motor using Field Oriented Control Method. Society of Instrument and Control Engineers, SICE Annual Conference. 2002: 264-267.

[6] S Jain, P Agrawal, H Gupta. "Genetic Algorithmled shunt active power filter for power quality improvement". in IEE Proceedings of the Electric Power Applications. 2002; 149: 317-28.

[7] Mariun Norman, Bahari Samsul, Noor Mohd, Jasni Jasronita, Omar SB. A Genetic Algorithmler for an Indirect vector Controlled Three Phase Induction Motor. Proceedings Analog and Digital Techniques in Electrical Engineering, TENCON 2004, Chiang Mai, Thailand. 2004; 4: 1-4.

[8] Afonso JL, Fonseca J, Martins JS, Couto CA. Genetic Algorithm Techniques Applied to the Control of a Three-Phase Induction Motor. Proceedings of the UK Mechatronics Forum International Conference, Portugal. 142-146.

[9] Chiewchitboon P, Tipsuwanpom P, Soonthomphisaj N, Piyarat W. Speed Control of Three-phase Induction Motor Online Tuning by Genetic Algorithm. Fifth International Conference on Power Electronics and Drive Systems, PEDS 2003. 2003; 1: 184-188.

[10] Parmod Kumar, Alka Mahajan. "Soft Computing Techniques for the Control of an Active Power Filter". IEEE Transactions on Power Delivery. 2009; 24(1): 452-461.

[11] Bouserhane Ismail K, Hazzab Abdeldjebar, Boucheta Abdelkrim, Benyounes Mazari, Mostefa Rahli. Optimal Fuzzy Self-Tuning of PI Controller Using Genetic Algorithm for Induction Motor Speed Control. Int. J. of Automation Technology. 2008; 2(2): 85-95. 
[12] Wang Guicheng, Zhang Min, Xinhe Xu, Jiang Changhong. Optimization of Controller Parameters based on the Improved Genetic Algorithms. IEEE Proceedings of the 6th World Congress on Intelligent Control and Automation, Dalian, China. 2006: 3695-3698.

[13] Thangaraj Radha, Thanga Raj Chelliah, Millie Pant, Abraham Ajit, Crina Grosan. Optimal gain tuning of PI speed controller in induction motor drives using particle swarm optimization. Logic Journal of IGPL Advance Access. 2010: 1-14.

[14] Pinto Joao OP, Bose Bimal K, Borges da Silva Luiz Eduardo. A Stator-Flux-Oriented VectorControlled Induction Motor Drive with Space-Vector PWM and Flux-Vector Synthesis by Neural Networks. IEEE Transaction on Industry Applications. 2001; 37(5): 1308-1318.

[15] Rajasekaran S, Pai GA Vijayalakshmi. Neural Networks, Genetic Algorithm and Genetic Algorithm: Synthesis and Applications. Prentice Hall of India, New Delhi, fifth printing. 2005.

[16] Raul Rojas. Neural Network- A Systematic Introduction. Spriger-Verlag, Berlin. 1996.

[17] Zerikat M, Chekroun S. Adaptation Learning Speed Control for a High-Performance Induction Motor using Neural Networks. Proceedings of World Academy of Science, Engineering and Technology. 2008; 35: 294-299.

[18] Kim Seong-Hwan, Park Tae-Sik, Yoo Ji-Yoon, Park Gwi-Tae. Speed-Sensorless Vector Control of an Induction Motor Using Neural Network Speed Estimation. IEEE Transaction on Industrial Electronics. 2001; 48(3): 609-614.

[19] Khalid Saifullah, Dwivedi Bharti. Comparison of Control Strategies for Shunt Active Power Filter under balanced, unbalanced and distorted supply conditions. Proceedings of IEEE Sponsored National Conference on Advances in Electrical Power and Energy Systems (AEPES-2013). 2013: 3741.

[20] Mauricio Aredes, Jurgen Hafner, Klemens Heumann. "Three-Phase Four-Wire Shunt Active Filter Control Strategies". IEEE Transactions on Power Electronics. 1997; 12(2): 311-318.

[21] Khalid Saifullah, Dwivedi Bharti. Power quality improvement of constant frequency aircraft electric power system using Genetic Algorithm, Genetic Algorithm and Neural network control based control scheme. International Electrical Engineering Journal (IEEJ). 2013; 4(3): 1098-1104.

[22] Khalid Saifullah, Dwivedi Bharti. Power Quality Issues, Problems, Standards \& their Effects in Industry with Corrective Means. International Journal of Advances in Engineering \& Technology (IJAET). 2011; 1(2): 1-11.

[23] Khalid Saifullah, Dwivedi Bharti. A Review of State of Art Techniques in Active Power Filters and Reactive Power Compensation. National Journal of Technology. 2007; 1(3): 10-18.

[24] RC Dugan, MF McGranaghan, HW Beaty. Electrical Power Systems Quality. New York: McGraw-Hill. 1996.

[25] Khalid Saifullah, Dwivedi Bharti. Power Quality: An Important Aspect. International Journal of Engineering, Science and Technology. 2010; 2(11): 6485-6490.

[26] IEEE Recommended Practices and Requirements for Harmonic Control in Electrical Power Systems, IEEE Standard. 1992: 519-1992.

[27] A Ghosh, G Ledwich, Power Quality Enhancement Using Custom Power Devices. Boston, MA: Kluwer. 2002.

[28] S Khalid, N Vyas. Application of Power Electronics to Power System, University Science Press, INDIA. 2009.

[29] Khalid Saifullah, Dwivedi Bharti. Comparative Critical Analysis of SAF using Soft Computing and Conventional Control Techniques for High Frequency $(400 \mathrm{~Hz})$ Aircraft System. Proceeding of IEEECATCON Conference. 2013: 100-110.

[30] Khalid S, Dwivedi B. GA-FUZZY application in SAF \& its comparative analysis with conventional techniques in aircraft system. 2013 International Conference on Control, Automation, Robotics and Embedded Systems (CARE), Jabalpur. 2013: 1-5

[31] Z Liyong, X Jian, Z Yidong, H Zhinan, Y Jianglong. Study on particle swarm optimization (PSO) for aircraft parameter identification based on BeiDou satellite system and strapdown AHRS integrated navigation. Guidance, Navigation and Control Conference (CGNCC), 2014 IEEE Chinese, Yantai. 2014: 2269-2274. 